\section{Acessibilidade geográfica à atenção primária à saúde em distrito sanitário do município de Salvador, Bahia}

\section{The geographical accessibility of primary health care in a sanitary district of the municipality Salvador, in the Brazilian State of Bahia}

Evanildo Souza da Silva Júnior 1

Maria Guadalupe Medina 2

Rosana Aquino 3

Ana Carla Freitas Fonseca 4

Ana Luiza Queiroz Vilasbôas 5

1 Secretaria da Saúde do Estado da Bahia. Av. Luis Vianna Filho, 400. Salvador, BA, Brasil. CEP: 41.745-900.

E-mail: evanildo_jr@yahoo.com.br

2-5 Instituto de Saúde Coletiva. Universidade Federal da Bahia. Salvador, BA, Brasil.

\begin{abstract}
Objectives: to assess the geographical accessibility of primary health care for the population served by the Community Health Agents Program (PACS) and the Family Health Program (PSF) in one sanitary district in the city of Salvador, Brazil.

Methods: a evaluative cross-sectional study was carried out. The data were collected using interviews with health workers from the eleven PACS and PSF teams. Analysis of the data took two factors into account: access of the population and the logic of territorialization.

Results: the district has a relatively rugged landscape and all the teams reported the existence of geographical barriers in the area, in particular steps and steep hills. There was no difference in accessibility between the PACS and the PSF. The process of territorialization was unrelated to the concept of territory as a process. Some areas covered by the teams were located some distance from the UBS and this constituted a significant obstacle to access.

Conclusions: the implantation of the PACS/PSF strategy in the district and the model of territorialization were not in line with the principles that should guide primary health care, resulting in geographical restrictions on access for the population served. It is recommended that the current territorial design be reviewed to ensure that it is more line with PSF guidelines and to enable better access to primary care.
\end{abstract}

Key words Health evaluation, Primary health care, Family Health Program

\section{Resumo}

Objetivos: avaliar a acessibilidade geográfica à atenção primária à saúde da população coberta pelos Programa de Agentes Comunitários de Saúde (PACS) e Programa de Saúde da Família (PSF) de um distrito sanitário de Salvador.

Métodos: estudo avaliativo transversal. Os dados foram coletados a partir de entrevistas realizadas junto aos profissionais das onze equipes de PACS e PSF. A análise dos dados contemplou duas dimensões: acesso da população e lógica de territorialização.

Resultados: o distrito apresentava relevo bastante acidentado $e$ todas as equipes informaram a existência de barreiras geográficas na área, em especial escadarias, morros e ladeiras. Não foi observada diferença significativa na acessibilidade às equipes de PACS e PSF. O processo de territorialização esteve dissociado da concepção de território-processo. Algumas áreas de abrangência das equipes situavamse em locais afastados das UBS, constituindo-se em importante barreira ao acesso da população.

Conclusões: o processo de implantação da estratégia PACS/PSF no distrito e o modelo de territorialização adotado não atenderam aos princípios que devem nortear a organização da atenção primária à saúde, resultando em restrições na acessibilidade geográfica da população coberta. Recomenda-se que seja realizada uma revisão do desenho atual da territorialização, visando uma melhor adequação às diretrizes do PSF e à promoção de uma maior acessibilidade à atenção primária.

Palavras-chave Avaliação em saúde, Atenção primária à saúde, Programa Saúde da Família 


\section{Introdução}

A criação do Sistema Único de Saúde (SUS), universal e com financiamento público, significou importante conquista da sociedade brasileira. Entretanto, a garantia do acesso aos serviços de saúde a todos os cidadãos permanece como desafio, assim como em vários países que possuem sistemas universais de saúde, mesmo no mundo desenvolvido. ${ }^{1}$ Uma das principais bandeiras dos movimentos sociais, a acessibilidade está relacionada à concepção de saúde como direito, intrínseca à condição de cidadania e constitui ação prioritária para a efetivação do SUS como pacto social.

Acesso representa o fator que intermedia a relação entre a procura por cuidados de saúde, a partir da percepção de uma necessidade de saúde pelos indivíduos, e a entrada no serviço. ${ }^{2} \mathrm{O}$ termo 'acesso' é compreendido na perspectiva do ingresso ou entrada no sistema, relacionado à utilização, ${ }^{3}$ enquanto que 'acessibilidade' vem sendo adotado, de uma maneira geral, como as características da oferta de serviços de saúde que contribuem de forma positiva ou negativa para a utilização dos serviços por parte dos usuários. 4 Entretanto, o conceito de 'acessibilidade' vem sendo ampliado, incorporando as características dos usuários na sua relação com os serviços de saúde, considerando a dimensão simbólica 5 e a aceitabilidade. 6 A posição que um indivíduo ocupa em um espaço social determinado e em uma dada situação de oferta de bens e práticas possíveis, será determinante para a realização de escolhas e para o consumo de bens e serviços culturais.?

Entre as dimensões de acessibilidade, destacamse duas, as quais estão interrelacionadas: a sócioorganizacional, que corresponde às características da oferta de serviços e que intervêm na relação entre características dos indivíduos e o uso de serviços, facilitando ou dificultando o acesso; e a dimensão geográfica, que reflete a distância percorrida pelos usuários até a obtenção dos cuidados de saúde, englobando a distância linear, tempo de locomoção e os custos relacionados ao deslocamento. 3,4

Os problemas relacionados à acessibilidade estão presentes em diversos contextos, destacando-se os fatores geográficos, desigualdades socioeconômicas e fatores relacionados à organização da oferta e à demanda. ${ }^{8}$ Entre os fatores geográficos, as barreiras naturais ou geradas a partir da transformação do espaço pela atividade humana ${ }^{9}$ e o tempo de deslocamento determinado pela distância percorrida constituem os principais obstáculos ao acesso dos usuários aos cuidados de saúde, pois representam a resistência imposta pelo espaço geográfico às trajetórias de deslocamento dos usuários em direção aos serviços ${ }^{2}$ ou aos locais onde se desenvolvem as ações de saúde.

De forma geral, os estudos acerca da acessibilidade vem privilegiando as dimensões organizacional e socioeconômicas, associadas, muitas vezes, à análise da utilização dos serviços, embora alguns autores agreguem aspectos da dimensão geográfica.9-11 Porém, longe de representar investigações de menor importância, estudos avaliativos da acessibilidade geográfica aos serviços de saúde são ferramentas essenciais de apropriação dos critérios e formas de delimitação dos territórios de atuação das equipes saúde, em especial de atenção primária e, portanto, essenciais para o planejamento de intervenções que representem possibilidades de reorganização do modelo assistencial, a partir de alterações do modo de produção em saúde. 12

A tomada de decisão acerca da localização e da amplitude dos serviços de atenção primária a serem ofertados em um território delimitado constitui grande desafio ao planejamento e programação em saúde. Características geográficas, socioeconômicas, culturais e políticas devem ser consideradas, superando a lógica tecnosanitarista tradicionalmente hegemônica no planejamento setorial. ${ }^{9}$

O Programa Saúde da Família (PSF), importante estratégia de mudança do modelo assistencial a partir da reorganização da atenção primária à saúde (APS), visa garantir o acesso da população ao sistema de saúde no nível local, atuando no território através da adscrição de clientela, do diagnóstico situacional e do planejamento de ações dirigidas aos problemas de saúde, de forma pactuada com a comunidade. 13 Considerando as profundas iniquidades em relação ao acesso aos serviços de saúde no país, em especial dos grupos populacionais mais vulneráveis, ${ }^{2} \mathrm{o}$ PSF se insere como importante intervenção para ampliação do acesso a essa população, principal beneficiária do programa.

A atuação sobre o território, a partir de sua concepção processual, constitui um dos pilares desta estratégia. O território-processo é compreendido como um espaço dinâmico, em permanente construção e reconstrução, onde os sujeitos estão postos em uma arena política, possuindo, além da dimensão natural (território-solo), as dimensões econômica, política, cultural e epidemiológica. ${ }^{14}$

No trabalho das equipes de saúde, o território microárea, definido segundo a lógica de homogeneidade socioeconômica-sanitária, adquire relevância como espaço privilegiado para o desenvolvimento de intervenções na perspectiva da vigilância da 
saúde. 15,16 Sua delimitação representa etapa essencial à organização do processo de trabalho das equipes e deve ser norteada pela perspectiva de garantia do acesso da população aos serviços e pela identificação dos riscos presentes no território. 15

Avaliar o processo de trabalho das equipes enfocando, especialmente, a acessibilidade geográfica é imprescindível para se avançar na consolidação do SUS, apoiando a gestão municipal no planejamento da ampliação de cobertura da estratégia PSF nos próximos anos e na reorganização dos serviços de saúde em nível local. Esse trabalho visa contribuir nessa direção, tendo como objetivo geral avaliar a acessibilidade geográfica à atenção primária da população coberta pelos programas Programa de Agentes Comunitários de Saúde / Programa de Saúde da Família (PACS/PSF) em um distrito sanitário do município de Salvador, e como objetivos específicos: caracterizar a distribuição espacial das unidades básicas de saúde (UBS) no território; descrever as principais barreiras geográficas relacionadas ao acesso dos usuários às UBS de referência das equipes; e discutir o processo histórico de apropriação do território por parte das equipes de saúde.

\section{Métodos}

Trata-se de um estudo descritivo, originado de uma avaliação normativa da APS desenvolvida pelo Instituto de Saúde Coletiva da Universidade Federal da Bahia em um distrito sanitário (DS) do município de Salvador. 17

$\mathrm{O}$ distrito estudado possui uma área de $6,74 \mathrm{~km}^{2}$, população estimada de 170.700 habitantes (2007). Caracteriza-se por forte herança africana, crescimento desordenado e com importantes limitações de infraestrutura e problemas sociais. Apresenta cinco UBS, sendo três Unidades de Saúde Convencionais (USC) e duas Unidades de Saúde da Família (USF). A cobertura do PACS no distrito era de $35 \%$, contando com cinco equipes, e $14 \%$ do PSF, com seis equipes. ${ }^{17} \mathrm{O}$ universo da pesquisa foi constituído pelas cinco UBS e as unidades de coleta e análise dos dados foram compostas pelas onze áreas das equipes, conforme a seguinte distribuição:

USC 1 - duas equipes de PACS, denominadas PACS $1 \mathrm{~A}$ e PACS $1 \mathrm{~B}$

USC 2 - uma equipe de PACS, denominada PACS $2 \mathrm{~A}$;

USC 3 - duas equipes de PACS, denominadas PACS $3 \mathrm{~A}$ e PACS $3 \mathrm{~B}$

USF 1 - duas equipes de PSF, denominadas equipe de saúde da família (ESF): ESF 1A e ESF 1B;
USF 2 - quatro equipes de PSF, denominadas ESF 2A, ESF 2B, ESF 2C e ESF 2D.

Neste estudo, acessibilidade foi compreendida como as características da organização da oferta dos serviços de saúde que contribuem para uma maior ou menor utilização desses serviços por parte dos usuários do sistema. Para a avaliação da acessibilidade geográfica das equipes, foi construída uma matriz de análise com duas dimensões: a) acesso da população, contemplando os critérios distância percorrida, tempo de deslocamento, forma de deslocamento (incluindo a disponibilidade de meios de transportes), presença de barreiras geográficas, custo do deslocamento e a distribuição geográfica das áreas cadastradas; b) processo de territorizalização, contemplando o critério lógica de territorialização.

A coleta de dados foi realizada em duas etapas. Inicialmente foram realizadas entrevistas com gerentes das UBS e enfermeiras das equipes. Essas entrevistas foram realizadas de forma individual, em local reservado e foi utilizado um questionário com perguntas fechadas e abertas aplicado a todos os sujeitos por residentes de medicina social durante o quarto trimestre de 2008. As informações levantadas nessa etapa foram processadas em uma planilha eletrônica (Excel) e foi realizada análise descritiva dos dados com geração de tabelas e gráficos.

Para complementação e aprofundamento das questões, foram realizadas entrevistas semi-estruturadas com dez enfermeiras, uma médica e três agentes comunitários de saúde, durante os meses de abril e maio de 2009, contemplando as onze equipes. Essas entrevistas foram realizadas individualmente (com exceção de uma equipe, na qual foram entrevistados uma enfermeira juntamente com três agentes comunitários de saúde em um único momento). Foi utilizado um roteiro com perguntas abertas abordando questões norteadoras relacionadas à acessibilidade geográfica, à descrição do processo histórico de territorialização destas áreas e à lógica que norteou esse processo. As questões foram lidas para todos os sujeitos no início de cada entrevista a fim de que estes tivessem conhecimento do conteúdo. A concordância em participar da pesquisa foi dada mediante assinatura do termo de consentimento livre e esclarecido. As informações obtidas a partir deste procedimento foram registradas em um diário de campo pelo entrevistador que, ao final de cada entrevista, leu as informações registradas para os sujeitos a fim de validação e complementações.

O processamento dos dados foi iniciado com a exploração das informações levantadas a partir da coleta de dados. Nesta etapa, foram identificadas evidências relacionadas a cada critério das duas 
dimensões da matriz de análise, organizadas por unidades de análise (as onze equipes). Com a identificação dessas evidências foram construídos argumentos para cada critério e, por fim, elaboradas as sínteses desses resultados por dimensão de análise. A análise da dimensão processo de territorialização foi realizada a partir da narrativa dos sujeitos que vivenciaram o processo histórico de implantação da estratégia PACS/PSF no distrito em estudo. Para tanto, foi redigido o relato de cada sujeito referente ao processo histórico de territorialização da área e, posteriormente, construída uma síntese desse processo. Nesta síntese buscou-se identificar os principais elementos que subsidiaram a territorialização a fim de se conhecer a lógica que norteou esse processo, numa perspectiva cronológica, discutindo com a norma preconizada.

Para a análise espacial da distribuição das UBS foi utilizado como ferramenta o aplicativo EpiMapa, a partir de dados fornecidos pela Secretaria Municipal de Saúde (SMS) referentes ao geoprocessamento do território. A partir dos mapas produzidos, foram analisadas a distribuição territorial das áreas cobertas pelas equipes de PACS e PSF e sua relação geográfica com as unidades de saúde de referência das equipes.

$\mathrm{Na}$ aplicação dos procedimentos da investigação foram respeitados os valores éticos, através da observância da Resolução 196/96 do Conselho Nacional de Saúde, bem como a submissão e aprovação da pesquisa pelo Comitê de Ética e Pesquisa do ISC (Parecer 029/08).

\section{Resultados}

Os resultados revelaram a existência de importantes problemas de acessibilidade geográfica à APS no distrito estudado. Todas as equipes referiram a presença de barreiras geográficas distribuídas em sua extensão territorial. Não foram identificadas diferenças significativas na acessibilidade geográfica entre as equipes de PACS e PSF, tendo, no entanto, uma USF apresentado melhor situação. De forma geral, os fatores que contribuíram para a situação encontrada foram as condições naturais e a forma de organização do espaço e o modelo de territorialização adotado.

O distrito sanitário apresenta relevo acidentado e irregular, associado a uma ocupação desordenada do território, com extensas áreas com carência de infraestrutura adequadas. Caracteriza-se pela presença de grande quantidade de encostas, ladeiras e escadarias espalhadas por toda sua extensão territorial.
Em relação à organização da oferta de serviços da APS, as cinco UBS estão distribuídas de forma desigual no território e, com exceção da USF 1, não possuem localização central em relação às áreas de abrangência das equipes. Observou-se também a ausência de unidades de saúde nas regiões nordeste e sudoeste do distrito. As áreas cobertas pelas onze equipes são fragmentadas, descontínuas e não contemplam as áreas mais carentes, identificadas a partir das zonas especiais de interesse social (ZEIS) (Figura 1).

A existência de ladeiras, escadarias, encostas e a distância percorrida foram relatadas pela maioria dos informantes como importantes barreiras ao acesso da população às UBS. Além dessas, a grande quantidade de vielas, nas quais não transitam veículos, e o alagamento das ruas quando chove foram destacados (Tabela 1).

A USF 1 está situada em uma rua principal, em área de baixada circulada por morros. Quando chove, essa rua principal alaga e inviabiliza o acesso à unidade. A área das duas equipes possui uma quantidade elevada de escadarias e encostas, além de valas a céu aberto ou cobertas por placas de concreto que muitas vezes se desprendem. Muitas microáreas são também formadas de vielas estreitas difíceis de transitar. A ESF 1B, além dessas barreiras geográficas, apresenta ladeiras. Nesta área, uma microárea encontra-se bastante distante da USF de referência, sendo que muitos moradores preferem se deslocar para a USC 3 em virtude de o trajeto ser mais plano e pela disponibilidade de transporte coletivo.

A USF 2 localiza-se em uma avenida com grande fluxo de veículos e com infraestrutura inadequada para pedestres, caracterizada por passeios estreitos e irregulares. Quando chove, as vias de acesso à USF ficam alagadas, com transbordamento dos canais de esgoto.

As áreas das quatro equipes apresentam problemas relacionados à existência de escadarias e ladeiras. A situação é menos dramática na área da ESF 2A, que situa-se mais próxima da unidade, enquanto as ESF $2 \mathrm{~B}$ e $2 \mathrm{C}$ localizam-se em áreas mais distantes da USF e contam também com a presença de vias com maior fluxo de veículos. No caso da ESF 2B, algumas ruas possuem valas de esgoto com cobertura de concreto, muita das quais soltas, com histórico de acidentes fatais na população. Por fim, a área da ESF 2D localiza-se predominantemente em um espaço plano, atrás da USF. Entretanto, o desenho da territorialização dessa área é bastante irregular, com algumas microáreas mais distantes.

As três USC localizam-se em áreas altas. 
Figura 1

Mapa da área do distrito sanitário com a identificação das unidades básicas de saúde e das áreas de abrangência das equipes de PACS e PSF. Salvador - Bahia, 2009.

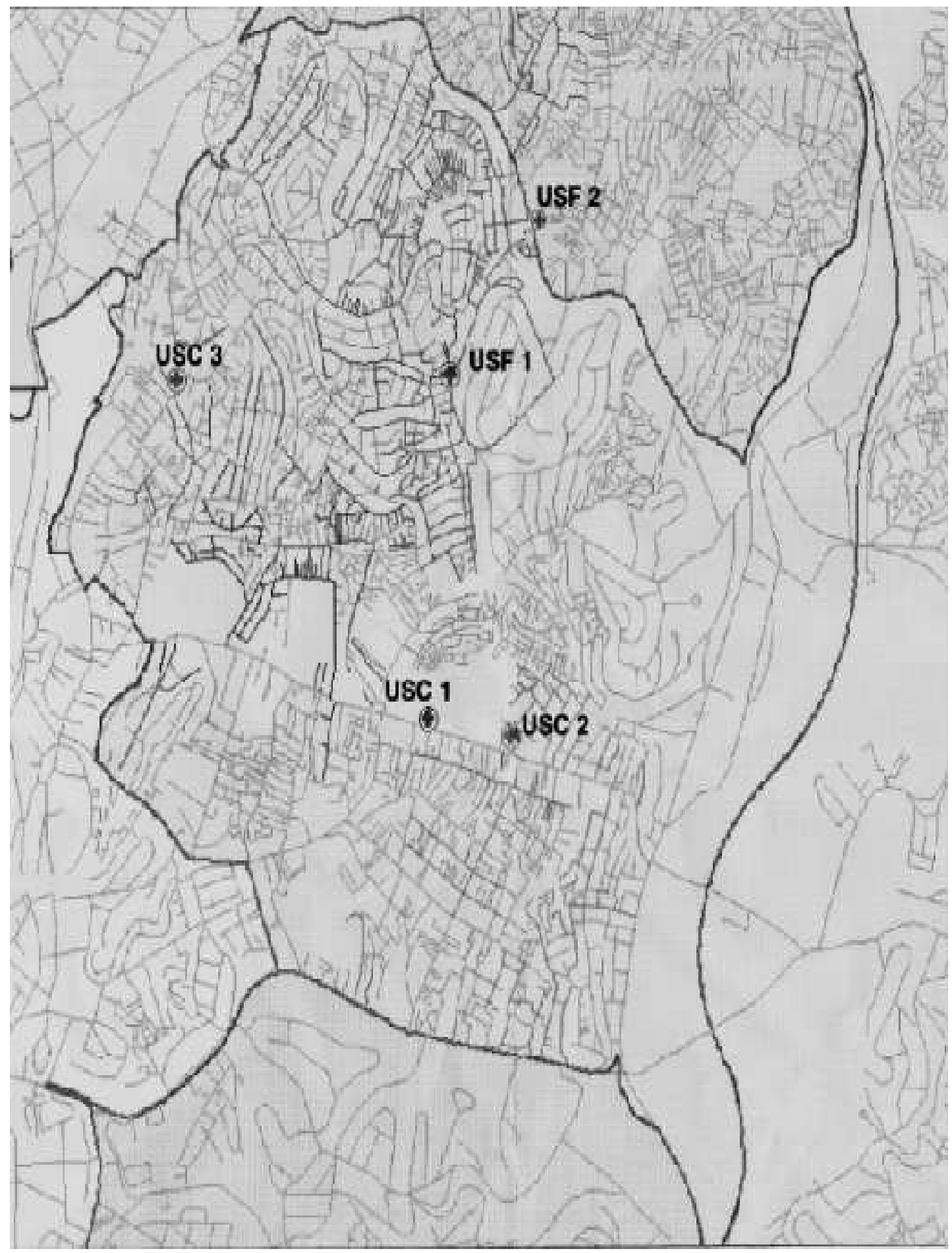

Fonte: Seplan/SMS/Siab, 2010

PACS= Programa de Agentes Comunitários de Saúde; PSF= Programa de Saúde da Família; USC= unidades de saúde convencionais; USF= unidades de saúde da família. 
Principais barreiras geográficas existentes nas áreas de abrangências das equipes de PACS e PSF. Salvador - Bahia, 2009.

\begin{tabular}{|c|c|c|c|c|c|c|c|}
\hline Equipe & Ladeira & Escadarias & Encostas & $\begin{array}{l}\text { Valas de } \\
\text { esgoto }\end{array}$ & $\begin{array}{c}\text { Avenida } \\
\text { movimentada }\end{array}$ & $\begin{array}{l}\text { Distância } \\
\text { percorrida }\end{array}$ & $\begin{array}{l}\text { Vielas/ } \\
\text { becos }\end{array}$ \\
\hline PACS $1 \mathrm{~A}$ & $x$ & $x$ & $x$ & & & $x$ & \\
\hline PACS 1B & & $x$ & $x$ & & & & \\
\hline PACS $2 A$ & $x$ & $x$ & $x$ & & $x$ & $x$ & \\
\hline PACS $3 A$ & $x$ & $x$ & $x$ & & & $x$ & \\
\hline PACS $3 B$ & $x$ & $x$ & $x$ & $x$ & $x$ & $x$ & \\
\hline ESF $1 \mathrm{~A}$ & & $x$ & $x$ & $x$ & & & $x$ \\
\hline ESF 1B & $x$ & $x$ & $x$ & & & $x$ & $x$ \\
\hline ESF $2 A$ & $x$ & $x$ & & $x$ & $x$ & & \\
\hline ESF 2B & $x$ & $x$ & & $x$ & & $x$ & \\
\hline ESF $2 C$ & $x$ & $x$ & & & $x$ & $x$ & \\
\hline ESF $2 D$ & $x$ & $x$ & $x$ & & $x$ & $x$ & $x$ \\
\hline
\end{tabular}

PACS= Programa de Agentes Comunitários de Saúde; PSF= Programa de Saúde da Família; ESF= equipe de saúde da família.

As USC 1 e 3 situam-se em locais centrais do DS e são unidades de grande porte e com alta demanda de usuários, não possuindo delimitação de clientela (exceto para as áreas cobertas pelo PACS). A USC 3 situa-se na avenida mais importante do DS, apresentando um fluxo de veículos intenso e multiplicidade de atividades comerciais. Já a USC 2 é uma unidade menor, localizada bem próxima à USC 1 (Figura 1).

A área da equipe PACS 1A é constituída basicamente de encostas. Em algumas microáreas mais distantes, a população prefere se deslocar até a USC 3 devido à maior facilidade de transporte. A equipe PACS 1B possui extensas áreas de encosta em que as ladeiras são cobertas por limo, ficando intransitáveis quando chove. A equipe PACS 3B possui algumas microáreas que, embora próximas à UBS, situam-se em terreno extremamente íngreme e de difícil acesso. Também são apontados outros problemas, como a presença de esgotos a céu aberto e lixões. Tais características dificultam o acesso das pessoas portadoras de necessidades especiais.

Apenas duas equipes puderam estimar a distância percorrida em quilômetros entre as microáreas mais distantes e a UBS de referência da equipe. Na equipe PACS 1B identificou-se que essa distância está entre cinco a seis quilômetros, enquanto na área
PACS 3B aponta-se de dois a três quilômetros.

Nas áreas de PACS, o tempo de deslocamento a pé entre as ruas mais distantes da UBS de referência da equipe foi sempre superior a 30 minutos, com exceção da área PACS 1B, com estimativa de 15 minutos. Já nas áreas de PSF, esse tempo de deslocamento foi bastante heterogêneo. Duas equipes estimaram 10 minutos (ESF 1A e 2A), três equipes estimaram 30 minutos (ESF 1B, 2B e 2D) e uma última equipe (ESF 2C), 40 minutos (Tabela 2). Entretanto, pontua-se que esses dados possuem precisão limitada em virtude da dificuldade de algumas informantes em mensurar esse tempo de deslocamento.

Vale ressaltar que algumas informantes referiram que o tempo de deslocamento era elevado, na maioria dos casos, em virtude do relevo acidentado da área. Assim, os pacientes precisam se deslocar de forma mais lenta e com maiores cuidados diante da presença de barreiras geográficas, principalmente idosos, gestantes e outros usuários portadores de necessidades especiais.

A principal forma de deslocamento utilizada pela população foi o deslocamento a pé, fato constatado em todas as equipes. Essa preferência estava mais relacionada ao custo do deslocamento, já que se tratam de áreas carentes e da própria distância da 
Tempo máximo, em minutos, de deslocamento até as unidades básica de saúde por equipe de PACS e PSF. Salvador Bahia, 2009.

\begin{tabular}{lcc} 
Equipe & Tempo a pé $(\mathbf{m i n})$ & Tempo de carro $(\mathbf{m i n})$ \\
\hline PACS 1A & 40 & 15 \\
PACS 1B & 15 & - \\
PACS 2A & 40 & - \\
PACS 3A & 40 & - \\
PACS 3B & 30 & - \\
ESF 1A & 10 & 10 \\
ESF 1B & 30 \\
ESF 2A & 10 & - \\
ESF 2B & 30 \\
ESF 2C & 40 & - \\
ESF 2D & 30
\end{tabular}

PACS= Programa de Agentes Comunitários de Saúde; PSF= Programa de Saúde da Família; ESF= Estratégia de Saúde da Família.

residência até as UBS do que da disponibilidade de transporte coletivo.

A Figura 2 mostra a distribuição das paradas de ônibus ao longo do distrito. Nela pode-se observar que a grande maioria das áreas cobertas pelo PACS/PSF não dispõem de transportes coletivos próximos às residências, decorrente, possivelmente, das próprias características de ocupação desordenada do território.

No caso das ESF, nenhuma dispunha de transporte coletivo direto para a USF. Este fato não foi apontado como importante problema de acesso às USF. Conforme alguns informantes, mesmo com disponibilidade de transportes coletivos, estes provavelmente não seriam utilizados pela maioria da população. Entretanto, em uma microárea da ESF 1B e na área ESF $2 \mathrm{~B}$ a disponibilidade desse recurso facilitaria o acesso, visto que se constituem áreas distantes da USF.

Mesmo nas áreas de PACS, que são em maioria mais distantes, também existe predominância da forma de deslocamento a pé, apesar da identificação da disponibilidade adequada de transportes coletivos (caracterizada pela variedade e frequência de linhas de ônibus) que facilitam o acesso daquelas áreas mais distantes da USC, com exceção da área PACS 2A. Nesta, microáreas mais distantes não possuiam disponibilidade de ônibus com frequência adequada (aproximadamente a cada 30 minutos) e o mesmo não transitava na rua onde está localizada a USC 2, tendo os usuários que caminhar cerca de 10 minutos do ponto de ônibus até a unidade.

Por fim, vale ressaltar que mesmo nas áreas onde existia disponibilidade adequada de transporte coletivo, os usuários precisavam, em muitos casos, ultrapassar barreiras geográficas, como ladeiras, encostas e escadarias, para chegarem à rua principal onde se localizam os pontos de parada dos ônibus.

Os custos relacionados ao deslocamento não foram considerados como importantes fatores de dificuldade de acesso às UBS no caso das áreas das ESF, provavelmente pela não disponibilidade de transportes coletivos. No caso das áreas cobertas pelo PACS, essa variável só não foi considerada importante pela enfermeira da equipe PACS 1B. Nas demais, identificou-se que o recurso financeiro necessário ao pagamento da tarifa do transporte representava uma barreira ao acesso dos usuários. No caso da área PACS $2 \mathrm{~A}$, alguns usuários residentes nas microáreas mais distantes preferiam deslocar-se até outra UBS, localizada fora do distrito sanitário, pelo fato do trajeto ser plano.

A implantação do PACS no distrito ocorreu de forma pouco organizada e dissociada da concepção 


\section{Figura 2}

Mapa da área do distrito sanitário com a identificação das unidades básica de saúde, das áreas de abrangência das equipes de PACS e PSF e com a distribuição dos pontos de ônibus. Salvador - Bahia, 2009.

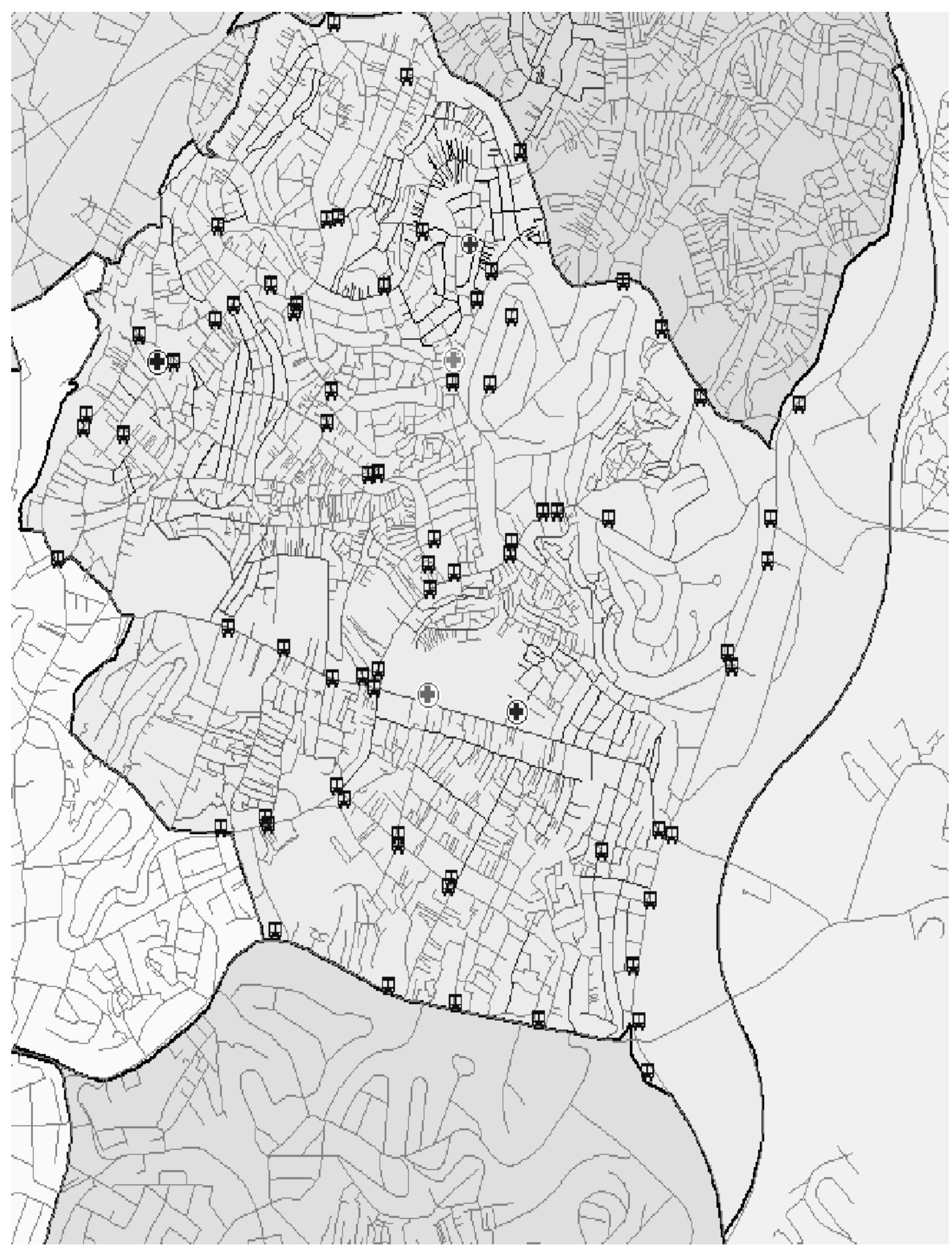

Fonte: Seplan/SMS/Siab, 2010

PACS = Programa de Agentes Comunitários de Saúde; PSF= Programa de Saúde da Família. 
do território como processo. A implantação do programa foi feita de forma vertical e centralizada, sem participação dos profissionais da rede de serviços da APS e sem critérios claros acerca dos princípios que deveriam nortear a territorialização, resultando em um desenho de territorialização deficiente.

A implantação das primeiras equipes de PACS ocorreu no ano de 1998 sob supervisão da coordenação do distrito. Os agentes comunitários de saúde (ACS), cuja seleção teve como principal critério a comprovação de moradia no DS, participaram de um treinamento básico sobre o preenchimento das fichas A e foram orientados a cadastrarem 150 residências em um prazo de 60 dias, sem maiores esclarecimentos acerca dos critérios que deveriam ser utilizados para a delimitação das microáreas. Após o cadastramento inicial das famílias, foram organizadas equipes com base nos bairros cadastrados.

Os critérios que subsidiaram a conformação das áreas de atuação das equipes não foram claros. Buscou-se cadastrar áreas consideradas como carentes e com maior risco social e epidemiológico sem, no entanto, discutir a lógica que deveria nortear a conformação das microáreas. Também não houve uma análise da situação de saúde como etapa preliminar à implantação e delimitação das áreas. A participação da comunidade foi tímida e pouco ativa, limitada à identificação de ruas ou residências mais carentes ou que necessitavam de maiores cuidados.

Depois de definidas as equipes, foram selecionadas enfermeiras da rede municipal de saúde, bem como de outros profissionais contratados através de empresas prestadoras de serviços (terceirização). Naquele momento, havia pouca informação acerca dos objetivos do programa e sobre a lógica que deveria nortear o processo de trabalho das equipes de PACS entre os sujeitos envolvidos.

O resultado dessa forma de implantação foi a configuração de uma territorialização deficiente, com a existência de graves distorções. As microáreas não eram contíguas, as equipes tinham áreas extensas e fragmentadas e muitos dos ACS nem ao menos residiam na área da equipe, existindo, inclusive, algumas microáreas localizadas em outros distritos.

Diante desse quadro, houve a necessidade de se reorganizar o desenho da territorialização. Nessa segunda etapa, buscou-se garantir a cobertura das ruas cadastradas inicialmente, considerando-se que as famílias contempladas anteriormente não deveriam ser excluídas do programa, mesmo nos casos em que eram identificadas microáreas descontínuas. Foram feitos remanejamentos de famílias e de ruas entre ACS intraequipes e permutas com outras equipes. A lógica utilizada nessa reestruturação foi a de contiguidade das microáreas, o número de famílias (150 famílias) e, de forma secundária, a residência dos ACS em sua microárea de atuação. Entretanto, esse terceiro critério não foi contemplado em todos os casos, em virtude das deficiências relacionadas ao desenho inicial. Durante os anos seguintes, foram incorporados novos agentes com o intuito de expandir a cobertura do programa.

Em 2004, houve a implantação das primeiras equipes de PSF. O local foi escolhido em virtude da presença de áreas de risco e subsidiado por uma análise da situação de saúde, bem como de reinvidicações da comunidade e dos profissionais de saúde. Para a implantação da nova estratégia, uma USC (que naquela época já era a unidade de referência de uma equipe de PACS) foi transformada em USF $1 \mathrm{e}$ nela foram locadas quatro equipes: ESF 1A, ESF 1B, ESF 2A e ESF 2B. Para a composição das equipes foram incorporados alguns ACS do PACS e contratados outros para completarem as equipes.

No entanto, as novas equipes formadas não mantiveram o desenho original de territorialização do PACS. Fizeram um novo mapeamento da área, com o remanejamento de algumas microáreas e a inclusão de outras. O cadastramento das famílias foi realizado após treinamento dos ACS e houve uma supervisão mais eficiente das enfermeiras e de técnicos da SMS que auxiliaram nesse processo. A implantação dessas equipes também culminou em mudanças nas áreas de outras equipes do PACS (em especial a equipe PACS 3A) em virtude do remanejamento de ACS e de microáreas. Ao final da definição das áreas das equipes, persistiram alguns problemas relacionados ao modelo de territorialização presente no distrito, bem como a existência de áreas bastante heterogêneas do ponto de vista topográfico e a dificuldade de se estabelecer limites entre as equipes.

Uma segunda mudança significativa relacionada à cobertura da estratégia saúde da família referiu-se à inauguração da USF 2 e a implantação de mais duas equipes (ESF 2C e ESF 2D) em 2007. Além dessas, as equipes ESF 2A e ESF 2B foram transferidas da USF 1 para essa nova unidade de saúde por determinação da SMS, sem uma discussão com os profissionais de saúde e da comunidade. Essas equipes mantiveram a mesma área de atuação. Parte dos ACS das duas novas equipes eram provenientes do PACS e outros foram selecionados. No entanto, na delimitação da área de atuação dessas novas equipes não foram mantidas as microáreas originais no PACS, com remanejamento e incorporação de 
novas ruas. Nesse processo, houve um maior apoio da equipe técnica da SMS, bem como da comunidade que já estava familiarizada com a lógica do programa. Vale ressaltar que essas duas equipes ainda se encontram em processo de territorialização, principalmente a ESF 2D que aguarda a contratação de um ACS para cobrir uma nova microárea. Os critérios utilizados continuaram sendo o da contiguidade, limite de famílias (agora 650 pessoas) e da residência do ACS na microárea.

\section{Discussão}

Este trabalho buscou avaliar a acessibilidade geográfica em áreas cobertas pelo PACS e PSF de um distrito sanitário de um dos maiores municípios brasileiros. Os resultados encontrados revelam, em primeiro lugar, o grande desafio em se realizar a territorialização em uma região tão heterogênea do ponto de vista do espaço natural. O relevo acidentado, associado à ocupação desordenada do espaço físico, geram um cenário bastante complexo e de difícil intervenção em relação aos problemas sociais, fato comum nas grandes metrópoles, em que o território urbano é estruturado a partir do binômio acumulação/miséria, evidenciado pela polarização de dois extremos: de um lado, a presença de áreas centrais, planejadas e assistidas de infraestrutura; de outro, periferias marginais, dependentes, improvisadas e carentes dos mais diversos bens e serviços de consumo coletivo. 18 No caso do distrito estudado, suas características geográficas impõem a necessidade de um maior esforço e criatividade na tentativa de se programar a oferta de ações de saúde tendo como objetivos a promoção da equidade e a garantia do acesso à saúde como direito.

A partir da observância dos princípios que norteiam a organização da atenção primária, em especial, a adscrição de clientela, pode-se analisar de forma crítica como o processo de implantação da estratégia PACS/PSF no distrito e o modelo de territorialização adotado, desvinculado das recomendações do Ministério da Saúde, 13 resultaram em um impacto aquém das expectativas em relação à acessibilidade geográfica da população coberta pelos dois programas (PACS e PSF). Nesse sentido, questionase se a forma de implantação dessa estratégia constituiu um processo de territorialização de fato, visto que se distancia completamente da norma preconizada. 13 Esse processo de implantação, ao não considerar a dinâmica do território, suas características e seu perfil de saúde-doença, representou uma atividade meramente burocrática: as áreas das equipes e suas microáreas constituíram-se apenas em espaços delimitados para atender às exigências formais de funcionamento dos programas.

O mapeamento inicialmente realizado no distrito gerou importantes entraves à organização da atenção primária, com repercussões negativas que se estendem até o presente momento. Mesmo com todo esforço e iniciativas em se reverter o processo, evidenciado pelos constantes remanejamentos de famílias e de microáreas entre equipes e de reorganização das áreas, tornando-as menos dispersas, observa-se que ainda existem grandes distorções, como a existência de ACS que nem ao menos moram na área da equipe, bem como de equipes sem limites precisos ou com áreas descontínuas.

Além dessas questões, pontua-se a possibilidade de uma apropriação limitada do território pelas equipes, evidenciada pela dificuldade de alguns informantes em responder às questões do roteiro de entrevista.

A forma centralizada de implantação do PACS também representou uma importante deficiência desse processo. Parece inconcebível pensar que a implantação de um programa que tem como importantes princípios a ampliação do acesso e o fortalecimento do controle social tenha sido realizada de forma vertical e distante dos atores interessados. Assim, acredita-se que um maior diálogo, tanto com a comunidade quanto com os profissionais de saúde, traria importantes benefícios e resultaria em uma territorialização mais próxima das necessidades de saúde da população. O processo de implantação das equipes de PSF avançou um pouco nessa questão sem, no entanto, representar uma iniciativa mais efetiva de ampliação da participação social.

Vale destacar que os esforços em se reorganizar o desenho de territorialização ainda carece de uma maior reflexão crítica acerca dos parâmetros utilizados. Observa-se que existe uma lógica estritamente normativa, dado que a definição das microáreas baseou-se exclusivamente no número máximo de pessoas por ACS. Assim, não foi observado no discurso das informantes uma percepção relacionada à lógica de constituição de microáreas a partir de uma análise de situação de saúde que identificasse áreas com certo grau de homogeneidade nas quais fosse possível intervir sobre os problemas de saúde a partir de uma discriminação positiva desses problemas. Este achado é corroborado em outro estudo, no qual se aponta que a lógica do mapeamento em áreas de implantação da ESF "ainda não atende à sua característica mais radical de inovação organizacional, na medida em que desconsidera o conceito de risco como nuclear para a compreensão desse processo".19 
Nessa discussão, há que considerar outro aspecto relevante. A existência de grandes aglomerados humanos, organizados de forma precária em um espaço tão heterogêneo como o distrito estudado, representa um grande desafio ao processo de territorialização. Nesse contexto, a delimitação desses espaços "mais ou menos homogêneos" em um espaço em que não existe uma delimitação clara de ruas, grupos populacionais e problemas sanitários, torna-se uma tarefa árdua e exige grande habilidade dos técnicos envolvidos.

Associado às dificuldades relacionadas à territorialização, a existência de apenas cinco UBS no distrito representam importante fator dificultante ao acesso à atenção primária, principalmente em relação à população atendida pelo PACS que está vinculada a apenas três USC, desigualmente localizadas no território.

Por fim, é preciso expor duas limitações desse estudo. Primeiro o fato de se desenvolver a partir da perspectiva dos profissionais e dos serviços de saúde, privilegiando a dimensão técnica (sanitaristaplanificador) da análise do acesso. 20 Desta forma, ressalta-se a necessidade de se investigar essa temática a partir da realidade dos usuários, descrevendo melhor a forma como as variáveis estudadas se comportam e interagem entre si.

Outra limitação diz respeito ao fato de o estudo ter se dedicado à análise da acessibilidade apenas para a população coberta pelo PACS/PSF. No entanto, tendo em vista que a presença de barreiras geográficas encontra-se disseminada em toda extensão territorial do distrito, além do pequeno número de UBS e de sua distribuição desigual pela área, presume-se que o acesso à atenção primária da população não cadastrada seja igualmente problemática.

No entanto, mesmo com essas limitações, pôdese observar que os resultados foram bastantes esclarecedores e conseguiram demonstrar as debilidades da acessibilidade à atenção primária em sua dimensão geográfica. Se considerarmos que, teoricamente, as áreas cobertas por esses programas deve- riam apresentar melhores condições de acesso da população, presume-se que a situação seja ainda mais difícil para as demais áreas.

Há de se considerar, como possibilidade a ser explorada, um modelo de expansão do PSF que adote a implantação das USF com a inserção de duas ou três equipes, cobrindo uma área menor. Esse modelo tenderia a facilitar a acessibilidade geográfica a partir da intervenção sobre a variável "distância percorrida" e, consequentemente, tempo de deslocamento, visto que a acessibilidade tende a ser maior entre destinos mais próximos, mesmo nos casos em que haja disponibilidade de meios de reduzir a distância. 18 Essa proposta é justificada pelo melhor resultado apresentado pela USF 1 em relação a essas variáveis.

Também se considera a necessidade de revisão do atual desenho da territorialização com vistas a uma melhor organização da assistência. Esse novo olhar deve ser pautado na percepção do território como processo dinâmico de relações e de expressão do processo saúde-doença. Há de se superar a lógica normativa de territorialização, pautada basicamente no número de pessoas por ACS, avançando na apropriação do território a partir de uma análise da situação de saúde.

Por fim, diante da carência de uma infraestrutura adequada, essas iniciativas setoriais não podem estar dissociadas de outras políticas sociais que tragam melhorias às condições de vida da população, principalmente em relação ao acesso de pessoas portadoras de necessidades especiais, que significou importante problema apontado neste estudo. Assim, há a emergência de ações intersetoriais visando associar os avanços obtidos através da reorganização dos serviços de saúde com outras iniciativas que tenham por objetivo melhorar o espaço físico onde essa população está inserida. Tratam-se de ações essenciais à melhoria das condições de vida da população, visto que a existência de desordens físicas, tanto no ambiente físico natural quanto no construído pela ação humana, refletem a deterioração do espaço urbano e relacionam-se a piores condições de saúde. ${ }^{21}$

\section{Referências}

1. Wilson K, Rosenberg MK. Accessibility and the Canadian health care system: squaring perceptions and realities. Health Policy. 2004; 67: 137-48.

2. Travassos C, Castro MSM. Determinantes e desigualdades sociais no acesso e na utilização dos serviços de saúde. In Giovanella L. et al. Políticas e sistema de saúde no Brasil. Rio de Janeiro: Fiocruz/CEBES; 2008.
3. Travassos C, Martins M. Uma revisão sobre os conceitos de acesso e utilização de serviços de saúde. Cad de Saúde Pública. 2004; 20 (supl) 2: 190-8.

4. Donabedian A. Los espacios de la salud: Aspectos fundamentales de la organización de la atención médica. 1 ed espanhola. México: Ed. Biblioteca de la Salud; 1988. 
5. Giovanella L, Fleury S. Universalidade da atenção à saúde: acesso como categoria de análise. In: Eibenschutz C, org. Política de saúde: o público e o privado. Rio de janeiro: Fiocruz; 1995. p. 177-98

6. Penchansky D, Thomas J. The concept of access: Definition and relationship to consumer satisfaction. Medical Care. 1981; 20: 127-40.

7. Cunha ABO. Acesso e utilização de serviços de saúde no Estado da Bahia [tese]. Salvador: Instituto de Saúde Coletiva da Universidade Federal da Bahia; 2007.

8. Vieira-da-Silva LM, Chaves SCL, Esperidião MA, LopesMartinho RM, Cardoso M, Silva PDF, Silva IVL, Santos ES, Souza DS, Paim LMM, Silva DO. Avaliação da acessibilidade à atenção básica no município de Salvador, Bahia (mímeo). Instituto de Saúde Coletiva; 2007.

9. Unglert CVS, Rosenburg C, Junqueira CB. Acesso aos serviços de saúde: uma abordagem de geografia em saúde pública. Rev Saúde Pública. 1987; 21: 439-46.

10. Unglert CVS. O enfoque da acessibilidade no planejamento da localização e dimensão de serviços de saúde. Rev Saúde Pública. 1990; 24: 445-52.

11. Remoaldo PC. Acessibilidade aos cuidados primários de saúde dos conselhos de Guimarães e de Cabeceiras de Basto. Rev Port Clin Geral. 2003; 19: 107-19.

12. Fekete MC. Estudo da acessibilidade na avaliação dos serviços de saúde. In: Santana JP. Desenvolvimento gerencial de unidades básicas do Sistema Único de Saúde. Brasília: OPS; 1997.

13. Brasil. Portaria GM 648/06. Política Nacional da Atenção Básica. Brasília, DF: Ministério da Saúde; 2006.

14. Mendes EV, Teixeira CF, Araújo EC, Cardoso MRL. Distrito sanitário: conceitos chaves. In: Mendes EV (org).
Distrito sanitário: o processo social de mudanças no Sistema Único de Saúde. São Paulo/Rio de Janeiro: HUCITEC-ABRASCO, 1995. p. 159-85.

15. Aquino R. Conhecendo o território. In: Aquino R, Medina MG, Vilasbôas AL, Baqueiro CCD, Nunes CA, Caputo MC, Fontoura MS, Pereira MSL, Tôrres TC. Manual para treinamento introdutório das equipes de saúde da família. Salvador: Pólo de Capacitação, Formação e Educação Permanente de Pessoal para a Saúde da Família; 2002.

16. Vilasbôas ALQ, Teixeira CF. Saúde da Família e Vigilância em Saúde: em busca da integração das práticas. Rev Bras Saúde Fam. 2007; 16: 63-7.

17. Aquino R. Relatório final da avaliação normativa das unidades básicas de saúde do Distrito Sanitário da Liberdade (mímeo). Salvador: UFBA / ISC; 2009.

18. Cardoso L, Matos R. Acessibilidade urbana e exclusão social: novas relações, velhos desafios. (s/d). [acesso: 28 jul. 2009] Disponível em: http://redpgv.coppe.ufrj.br/ arquivos/Acessibilidade_e_Exclusao_SIMPURB2007.pdf Data

19. Medina MG, Hartz ZMA. The role of the family health program in the organization of primary care in municipal health systems. Cad Saúde Pública. 2009; 25: 1153-67.

20. Abreu-de-Jesus WL, Assis MMA. Revisão sistemática sobre o conceito de acesso nos serviços de saúde: contribuições do planejamento. Ciên Saúde Coletiva. 2010; 15: $161-70$.

21. Santos SM. Desigualdades socioespaciais em saúde: incorporação de características da vizinhança nos modelos de determinação em saúde. In: Barcelos C, org. A geografia e o contexto dos problemas de saúde. Rio de Janeiro: ABRASCO; 2008.

Recebido em 5 de abril de 2010

Versão final apresentada em 28 de setembro de 2010

Aprovado em 30 de setembro de 2010 